\title{
Etanercept restores normal insulin signal transduction in $\beta 2$-adrenergic receptor knockout mice
}

\author{
Youde Jiang ${ }^{1}$, Qiuhua Zhang ${ }^{1}$, Eun-Ah Ye ${ }^{1}$ and Jena J Steinle $1,2,3,4^{*}$
}

\begin{abstract}
Background: Inhibition of TNFa protects the retina against diabetic-like changes in rodent models. The mechanism by which TNFa induces deleterious retinal changes is not known. Previously, we have shown that TNFa can inhibit normal insulin signal transduction, leading to increased apoptosis in both retinal endothelial cells (REC) and Müller cells. Additionally, $\beta 2$-adrenergic receptor knockout mice ( $\beta 2 \mathrm{KO}$ ) have increased TNFa levels and decreased insulin receptor activity. In this study, we hypothesized that inhibition of TNFa in $\beta 2 \mathrm{KO}$ mice would increase normal insulin signaling, leading to improved retinal function.
\end{abstract}

Methods: C57BL6 or $\beta 2 \mathrm{KO}$ mice were left untreated or treated with etanercept ( $0.3 \mathrm{mg} / \mathrm{kg}$ subcutaneously, $3 \times$ a week) for 2 months. Electroretinogram analyses were done before treatment was initiated and after two months of treatment with etanercept on all mice. Western blot or ELISA analyses were done on whole retinal lysates from all four groups of mice for TNFa, suppressor of cytokine signaling 3 (SOCS3), insulin receptor, and apoptotic proteins.

Results: Etanercept significantly reduced TNFa levels in $\beta 2 \mathrm{KO}$ mice, leading to increased insulin receptor phosphorylation on tyrosine 1150/1151. SOCS3 levels were increased in $\beta 2 K O$ mice, which were reduced after etanercept treatment. Pro-apoptotic proteins were reduced in etanercept-treated $\beta 2 \mathrm{KO}$ mice. Etanercept improved ERG amplitudes in $\beta 2 \mathrm{KO}$ mice.

Conclusions: Inhibition of TNFa by etanercept protects the retina likely through reduced TNFa-mediated insulin resistance, leading to reduced apoptosis.

Keywords: TNFa, SOCS3, Apoptosis, Insulin signaling

\section{Background}

The role of sympathetic nerves in diabetes has not been questioned when focusing on peripheral nerve disease [1]. Work has demonstrated that diabetes and aging can both produce significant remodeling of sympathetic ganglia and neurotransmission [2]. However, the role of sympathetic nerve activity in the retina is less clear. Work by our group demonstrated that loss of dopamine beta hydroxylase (a key enzyme required for the production of norepinephrine) produces substantial changes to the retina [3]. Subsequently, we have shown that $\beta$-adrenergic

\footnotetext{
* Correspondence: jsteinl1@uthsc.edu

'Department of Ophthalmology, University of Tennessee Health Science Center, Memphis, TN, USA

${ }^{2}$ Department of Anatomy \& Neurobiology, University of Tennessee Health

Science Center, Memphis, TN, USA

Full list of author information is available at the end of the article
}

receptors are key to retinal damage, which is similar to retinal changes observed in animal models of diabetic retinopathy $[4,5]$. Recently, we showed that treatment of $\beta 2 \mathrm{KO}$ mice with a novel $\beta 1 / \beta 2$-adrenergic receptor agonist, Compound 49b, could prevent impaired insulin receptor signal transduction [6] observed in both diabetic rodent models [7], as well as retinal endothelial [8] and Müller cells [9] grown under hyperglycemia conditions. Retinal endothelial cells express only $\beta 1$ and $\beta 3$-adrenergic receptors [10], while retinal Müller cells express both $\beta 1$ - and $\beta 2$-adrenergic receptors [11]. Therefore, use of the $\beta 2$-adrenergic receptor knockout mice $(\beta 2 \mathrm{KO})$ mice could suggest that the retinal changes observed in these mice are produced by retinal endothelial cells through activation of $\beta 1$ - and/or $\beta 3$ adrenergic receptor signaling. Since we have shown that 
retinal endothelial cells have increased apoptosis in response to high glucose and impaired insulin signaling, it is likely that impaired insulin signaling may be key to apoptosis in the retina [8].

In our previous work in retinal endothelial cells, we have reported that high glucose increases TNF $\alpha$ levels, leading to apoptosis of these cells [8]. Others have also reported that increased cytokine levels can lead to apoptosis of retinal endothelial cells [12]. Increased TNF $\alpha$ can produce insulin resistance in multiple ways. The most direct pathway of TNF $\alpha$-induced inhibition of insulin signaling is through TNF $\alpha$-mediated phosphorylation of insulin receptor substrate 1 (IRS-1) on serine 307 [13]. Phosphorylation of serine 307 on IRS-1 inhibits the ability of IRS-1 to transmit the insulin phosphorylation signal to Akt, thus blocking normal insulin signal transduction. In addition to actions on IRS-1, TNFo also leads to increased suppressor of cytokine signaling 3 (SOCS3) levels $[14,15]$. Increased SOCS3 levels can phosphorylate the insulin receptor on tyrosine 960 which blocks the insulin receptor/IRS-1 interaction [16]. We have previously reported that TNF $\alpha$ and SOCS3 are both increased in response to high glucose in retinal endothelial cells, leading to increased phosphorylation of IRS-1 ${ }^{\text {Ser307 }}$ and $\operatorname{IR}^{\mathrm{Tyr} 960}$ [8]. The remaining question was whether this occurred in vivo and whether inhibition of TNFa could block all downstream responses to restore normal insulin signal transduction.

The suggestion of inhibition of TNF $\alpha$ as a therapeutic for diabetic retinopathy is not novel. Because TNF $\alpha$ is reported to cause insulin resistance in many other tissues, including adipocytes [13] and myeloid progenitor cells [17], it would be expected that inhibition of TNFa would protect cells and normalize insulin signaling. This was directly tested in chronic studies in TNF $\alpha$ receptor 1- or receptor 2-deficient mice fed $30 \%$ galactose for up to 20 months. The authors found that inhibition of TNF $\alpha$ with etanercept (Enbrel), a TNF $\alpha$ receptor antagonist, in galactosemic rats led to reduced pericyte loss and degenerate capillary formation [18]. Additionally, in acute studies of retinopathy-like changes, the authors demonstrated that etanercept suppressed caspase activity and apoptosis in Long Evans rats treated with streptozotocin to make them diabetic [18]. Previously, this group had reported that etanercept reduced leukocyte adhesion in diabetic rats [19]. Therefore, it is clear that inhibition of TNF $\alpha$ is protective against diabetic retinopathy changes; however, the mechanism by which this may occur is unknown.

Our hypothesis was that inhibition of TNF $\alpha$ actions in $\beta 2 \mathrm{KO}$ mice would restore normal insulin signal transduction, explaining the improvement in markers of diabetic retinopathy reported by others. To test our hypothesis, we treated wildtype mice or $\beta 2 \mathrm{KO}$ mice with etanercept for two months and measured proteins involved in insulin resistance and signaling, including TNF $\alpha$, SOCS3, insulin receptor (IR), and apoptotic markers. We found that inhibition of TNF $\alpha$ by etanercept treatment to $\beta 2 \mathrm{KO}$ mice was able to significantly reduce apoptotic markers through decreased activation of TNF $\alpha$-mediated insulin resistance.

\section{Methods}

Mice

All mice experiments, including those for dark-adaptation and tail electrodes for electroretinogram (ERG) analyses, were approved by the Institutional Animal Care and Use Committee at the University of Tennessee Health Science Center (Protocol \#1992). $\beta 1 / \beta 2 K O$ mice $\left(A d r b 1^{\text {tml }} B k k\right.$ $\left.A d r b 2^{t m 1} B k k / \mathrm{J}\right)$ were purchased from Jackson Laboratories (Bar Harbor, ME, USA). From the $\beta 1 / \beta 2 \mathrm{KO}$ mice, we bred mice to generate only homozygous $\beta 2 \mathrm{KO}$ mice. We appreciate that C57BL6 may not be the ideal wildtype control, but the original $\beta 1 / \beta 2 \mathrm{KO}$ mice were from a mixed background containing C57BL6, therefore we chose the C57BL6 for wildtype. Since we use these mice at three months of age, other issues from the C57BL6 background should be minimized. We have previously published use of this animal model and genotyping [5] to demonstrate that neuronal markers of diabetic retinopathy are present, as well as increased apoptosis in the retina.

\section{Etanercept (Enbrel) treatment}

A subset of the $\beta 2 \mathrm{KO}$ mice were administered Enbrel by subcutaneous injection $0.3 \mathrm{mg} / \mathrm{kg}, 3 \times /$ week) [19]. After the final treatment, C57BL6 control, C57BL6+ etanercept, $\beta 2 \mathrm{KO}$ mice, and $\beta 2 \mathrm{KO}$ mice + etanercept (five mice of each gender in each group) were dark-adapted for ERG analyses prior to sacrifice by ketamine and xylazine overdose.

\section{Electroretinogram}

Prior to sacrifice for morphological and biochemical analyses, animals were subjected to ERG analyses to evaluate the changes in the electrical activity of the retina as we have done previously [5,7]. After dark-adaptation overnight, ERG responses were recorded from both eyes together using platinum wire corneal electrodes, forehead reference electrode, and ground electrode in the tail. Pupils were fully dilated using $1 \%$ tropicamide solution (Alcon, Ft. Worth, TX, USA). Methylcellulose (Celluvise; Allergan, Irvine, CA, USA) drops were applied as well to maintain a good electrical connection and body temperature was maintained at $37^{\circ} \mathrm{C}$ by a water-based heating pad. ERG waveforms were recorded with a bandwidth of 0.3 to $500 \mathrm{~Hz}$ and sampled at $2 \mathrm{kHz}$ by a digital acquisition system and were analyzed using a custom-built program (MatLab, Mathworks, Natick, 
MA, USA). Statistics were done on the mean \pm SD amplitudes of the A- and B-wave of each treatment group.

\section{Western blot analysis}

Equal amounts of protein from the tissue extracts were separated on the pre-cast tris-glycine gel (Invitrogen, Carlsbad, CA, USA), blotted onto a nitrocellulose membrane. After blocking in TBST (10 mM Tris- $\mathrm{HCl}$ buffer, $\mathrm{pH}$ 8.0, $150 \mathrm{mM} \mathrm{NaCl}, 0.1 \%$ Tween 20) and 5\% (w/v) $\mathrm{BSA}$, the membrane was treated with appropriate primary antibodies followed by incubation with secondary antibodies labeled with horseradish peroxidase. Antigenantibody complexes were detected by a chemiluminescence reagent kit (Thermo Scientific, Waltham, MA, USA). Primary antibodies used were phosphorylated Akt (Serine 473), Akt, Bax, Bcl-xL, Cytochrome C, SOCS3, phosphorylated insulin receptor (tyrosine 1150/1151), insulin receptor (all purchased from Cell Signaling, Danvers, MA, USA), insulin receptor phosphorylated on Tyr960 (Cell Applications, San Diego, CA, USA), and beta actin (Santa Cruz Biotechnology Inc., Santa Cruz, CA, USA).

\section{ELISA analysis}

A cleaved caspase 3 ELISA (Cell Signaling, Danvers, MA, USA) was used to measure levels of the active apoptotic marker in whole retinal lysates. TNF $\alpha$ protein concentrations were measured using a TNF $\alpha$ ELISA (ThermoFisher, Pittsburgh, PA, USA). For cleaved caspase 3 ELISA analyses, equal protein was loaded $(50 \mu \mathrm{g})$ into all wells to allow for comparisons based on optical density (OD). For the TNF $\alpha$ ELISA, $50 \mu$ l protein was loaded into all wells, with analyses for concentrations based on a standard curve.

\section{Statistics}

Statistical analyses were done using Prism software (GraphPad, La Jolla, CA, USA). Analyses were done using a Kruskal-Wallis test, followed by Dunn's test. Data are presented as mean \pm SEM. For Western blots, a representative blot is presented.

\section{Results}

Etanercept treatment restores normal insulin receptor phosphorylation, while reducing IRS-1 ${ }^{\text {Ser307 }}$ levels

To insure that treatment with etanercept was able to significantly reduce TNF $\alpha$ levels in $\beta 2 \mathrm{KO}$ mice, we performed an ELISA analysis to show that $\beta 2 \mathrm{KO}$ mice have increased levels of TNF $\alpha$, which were significantly reduced by etanercept treatment (Figure 1A). Since TNF $\alpha$ is a key player in insulin resistance, we wanted to investigate whether blockade of TNF $\alpha$ actions in $\beta 2 \mathrm{KO}$ mice could prevent these deleterious effects. Etanercept treatment to $\beta 2 \mathrm{KO}$ mice was able to significantly increase insulin receptor autophosphorylation on tyrosine 1150/ 1151 (Figure 1B). Since TNF $\alpha$ preferentially phosphorylates IRS-1 on serine 307 to inhibit insulin signal transduction [13], we measured IRS-1 ${ }^{\text {Ser307 }}$ phosphorylation after etanercept treatment. Data showed that etanercept significantly reduced IRS-1 ${ }^{\text {Ser307 }}$ phosphorylation in $\beta 2 \mathrm{KO}$ mice (Figure $1 \mathrm{C}$ ), suggesting that treatment with etanercept prevented TNFo-induced IRS-1 phosphorylation.

\section{Etanercept reduced SOCS3 levels, leading to decreased IR $^{\text {Tyr960 }}$ phosphorylation}

We have previously reported that $\beta 2 \mathrm{KO}$ mice have increased SOCS3 levels and $\mathrm{IR}^{\mathrm{Tyr} 960}$ phosphorylation [5], which are both associated with increased TNF $\alpha$ levels

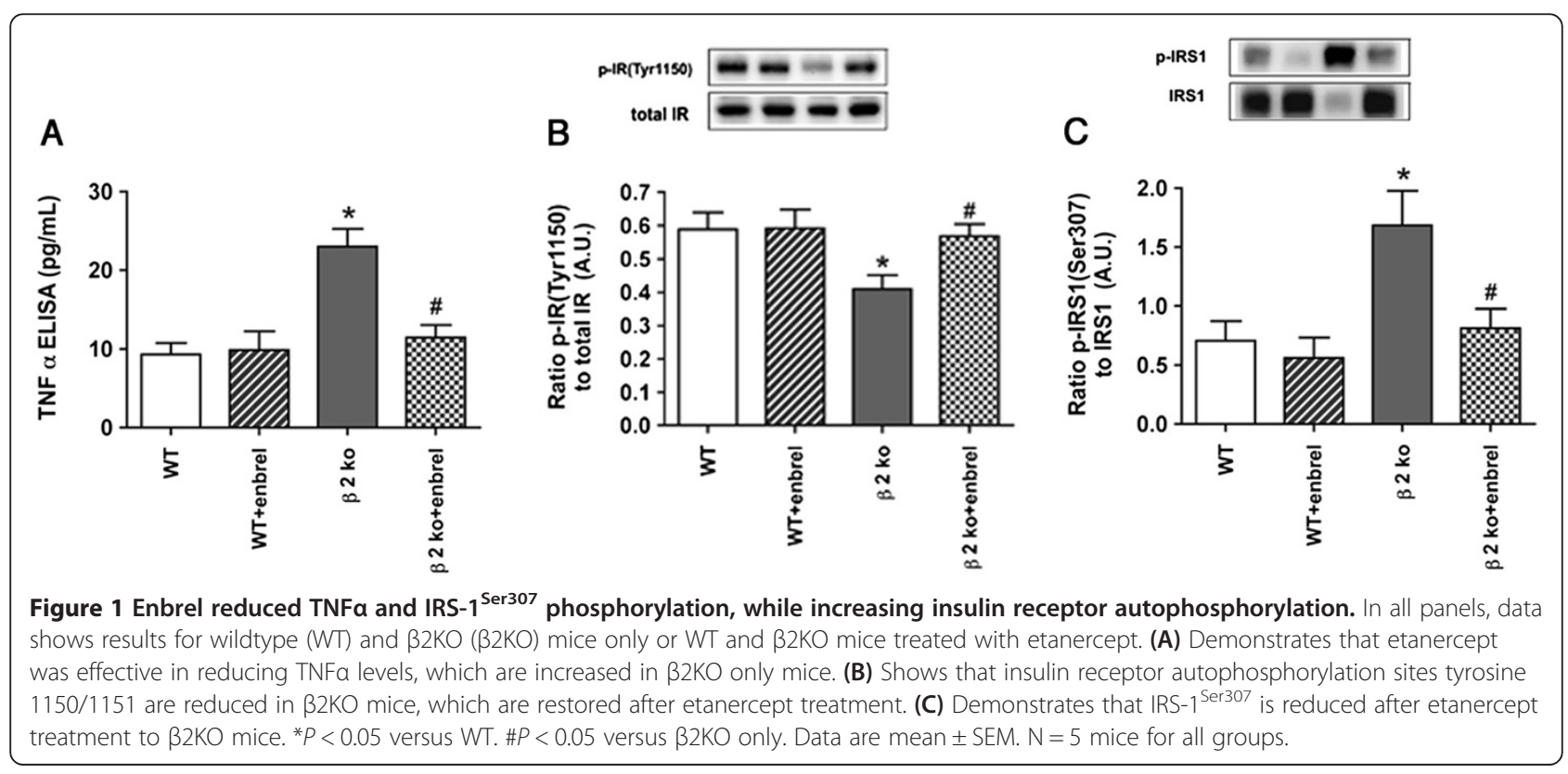


and insulin resistance [15,16]. Figure 2 demonstrated that $\beta 2 \mathrm{KO}$ mice have increased SOCS3 (A) and $\mathrm{IR}^{\mathrm{Tyr} 960}$ phosphorylation (B), as we reported previously. Additionally, Figure 2 showed that inhibition of TNFa with etanercept was able to significantly reduce both SOCS3 and $\mathrm{IR}^{\mathrm{Ty} 960}$ activity, suggesting that etanercept may prevent insulin resistance in the retina.

\section{Pro-apoptotic factors are reduced after etanercept treatment to $\beta 2 K O$ mice}

Since prevention of apoptosis is a key goal of the insulin signaling pathway, we measured key pro-apoptotic (Figure 3C-E) and anti-apoptotic markers (Figure 3A-B) in wildtype and $\beta 2 \mathrm{KO}$ mice. While etanercept had no effects on wildtype mice, etanercept treatment significantly increased levels of key anti-apoptotic markers, Akt (A) and Bcl-xL (B), while decreased pro-apoptotic markers, Bax (C), Cytochrome $C(D)$, and cleaved caspase 3 (E). Taken together, the data suggest that $\beta 2 \mathrm{KO}$ mice have impaired insulin signaling, which is restored after inhibition of TNF $\alpha$ through etanercept therapy.

\section{Etanercept treatment improves ERG amplitudes}

We have previously reported that $\beta 2 \mathrm{KO}$ mice have reduced amplitudes of the A-wave, B-wave and oscillatory potentials [5], which was improved with treatment with Compound 49b (Jiang et al., in press). In this study, we found a similar reduction in ERG amplitudes in $\beta 2 \mathrm{KO}$ mice compared to wildtype mice (Figure 4, red line), which was resolved with treatment with etanercept for two months (Figure 4, green line). Combining the cell signaling data with functional data, this work demonstrated that TNFa inhibition is effective in preventing insulin resistance in the retina, leading to normal retinal function.

\section{Discussion}

The goal of this study was to demonstrate that TNFa plays a role in insulin resistance in $\beta 2 \mathrm{KO}$ mice. Since others had reported that etanercept was effective in eliminating diabetic-like changes in the rodent eye $[18,19]$, we wanted to determine if inhibition of TNF $\alpha$ with etanercept in $\beta 2 \mathrm{KO}$ mice could restore normal insulin signal transduction. We have previously demonstrated that TNF $\alpha$ is key to inhibition of insulin signaling in both retinal endothelial cells (REC) [8] and Müller cells [20] grown in a high glucose concentration, leading to increased apoptosis. In this data set, we demonstrate that etanercept is effective at reducing TNF $\alpha$ mediated insulin resistance. Two months of etanercept treatment, used at the same treatment regimen as that used in humans with rheumatoid arthritis [19], led to a significant decrease in TNF $\alpha$ in $\beta 2 \mathrm{KO}$ mice when compared to untreated $\beta 2 \mathrm{KO}$ mice. Since we have reported that one pathway by which TNFa can mediate insulin resistance in REC is through phosphorylation of IRS$1^{\text {Ser307 }}[8]$, we measured this phosphorylation site in vivo and found that etanercept reduced IRS-1 ${ }^{\operatorname{Ser} 307}$ in the $\beta 2 \mathrm{KO}$ mice. Another potential pathway by which TNF $\alpha$ can mediate impaired insulin signaling is through activation of SOCS3 [15]. Etanercept was able to significantly reduce SOCS3 in $\beta 2 \mathrm{KO}$ mice, leading to decreased $I^{\text {Tyr960 }}$. Blockade of $I^{\text {Tyr960 }}$ phosphorylation can promote normal insulin signaling as $\mathrm{IR}^{\mathrm{Ty} 960}$ inhibits the interaction between insulin receptor and IRS-1 [16].

In addition to blockade of TNF $\alpha$-mediated impairment of insulin signal transduction, etanercept also promoted
A

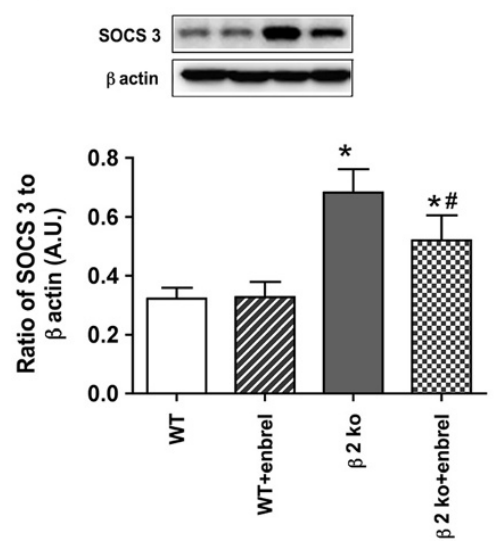

B
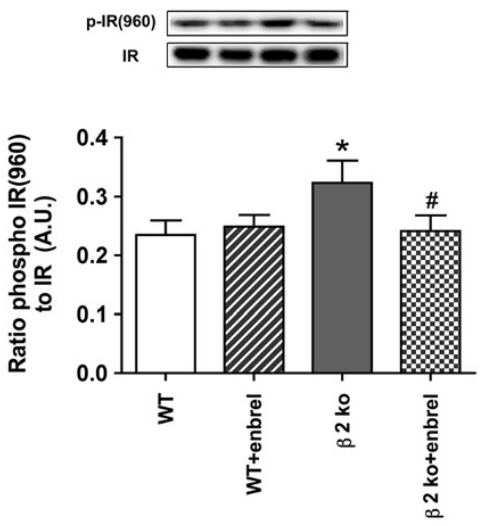

Figure 2 Inhibition of TNFa with etanercept reduces suppressor of cytokine signaling 3 (SOCS3) and IR ${ }^{\text {Tyr960 }}$ levels. In all panels, data shows results for wildtype (WT) and $\beta 2 \mathrm{KO}(\beta 2 \mathrm{KO})$ mice only or WT and $\beta 2 \mathrm{KO}$ mice treated with etanercept. (A) Western blot data on SOCS3 levels demonstrating that etanercept reduced SOCS3 levels in $\beta 2 \mathrm{KO}$ mice. (B) Western blot data on insulin receptor phosphorylation on tyrosine 960 , showing that $\mathbb{R}^{\mathrm{T} y r 960}$ is reduced after etanercept treatment. ${ }^{*} P<0.05$ versus $W T$. $\# P<0.05$ versus $\beta 2 \mathrm{KO}$ only. Data are mean $\pm \mathrm{SEM}$. $\mathrm{N}=5$ mice for all groups. 


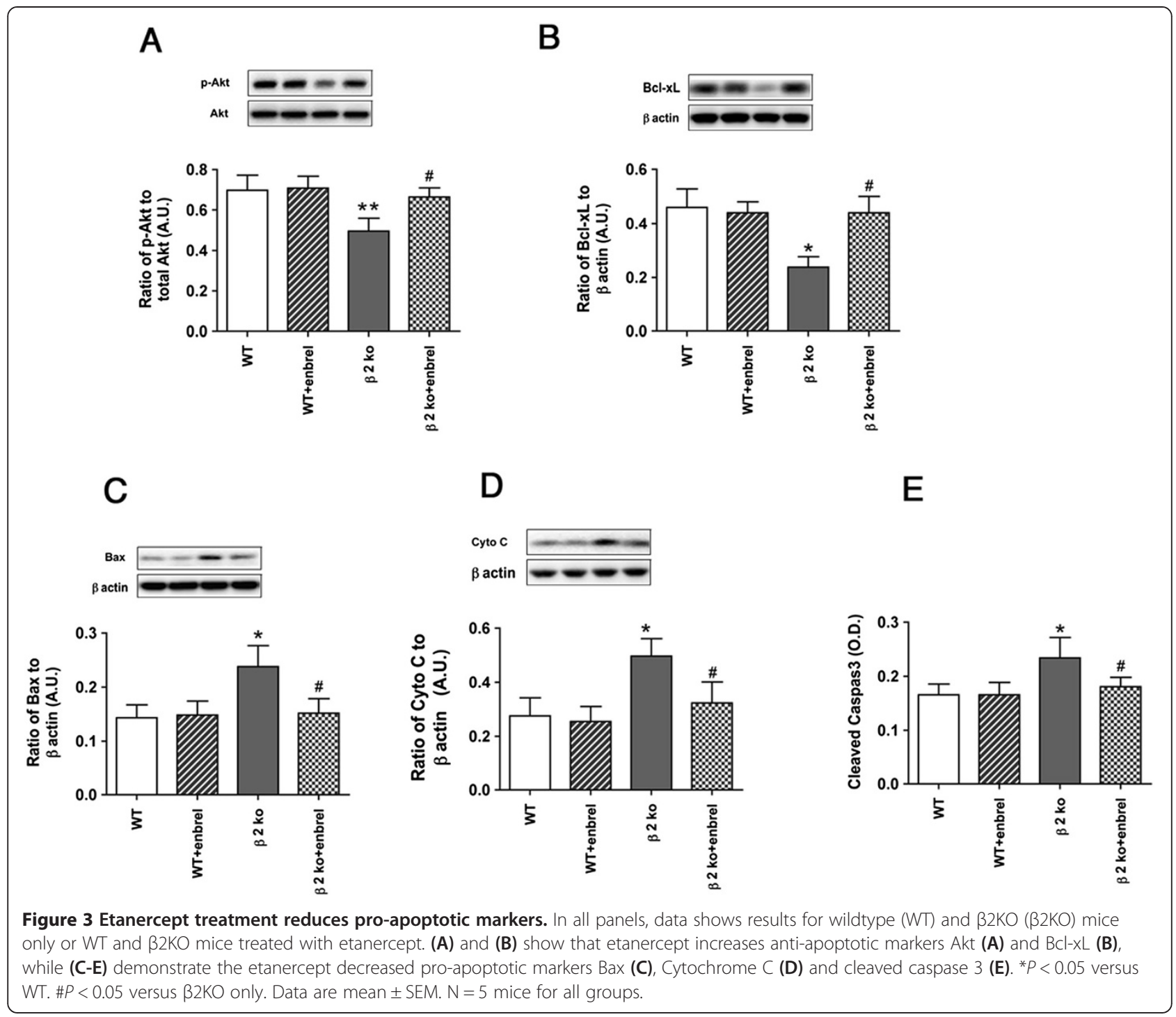

phosphorylation of insulin receptors on tyrosine 1150/ 1151 in the $\beta 2 \mathrm{KO}$ mice, which are autophosphorylation sites, leading to promotion of insulin signaling. We have previously reported that insulin receptor phosphorylation is reduced in $\beta 2 \mathrm{KO}$ mice, which appeared to be localized to the inner retina and ganglion cell layer [5]. Maintenance of normal insulin signal phosphorylation by etanercept likely led to increased Akt activity and decreased cleaved caspase 3 observed in the $\beta 2 \mathrm{KO}$ mice. The reduced apoptosis and improvement in insulin

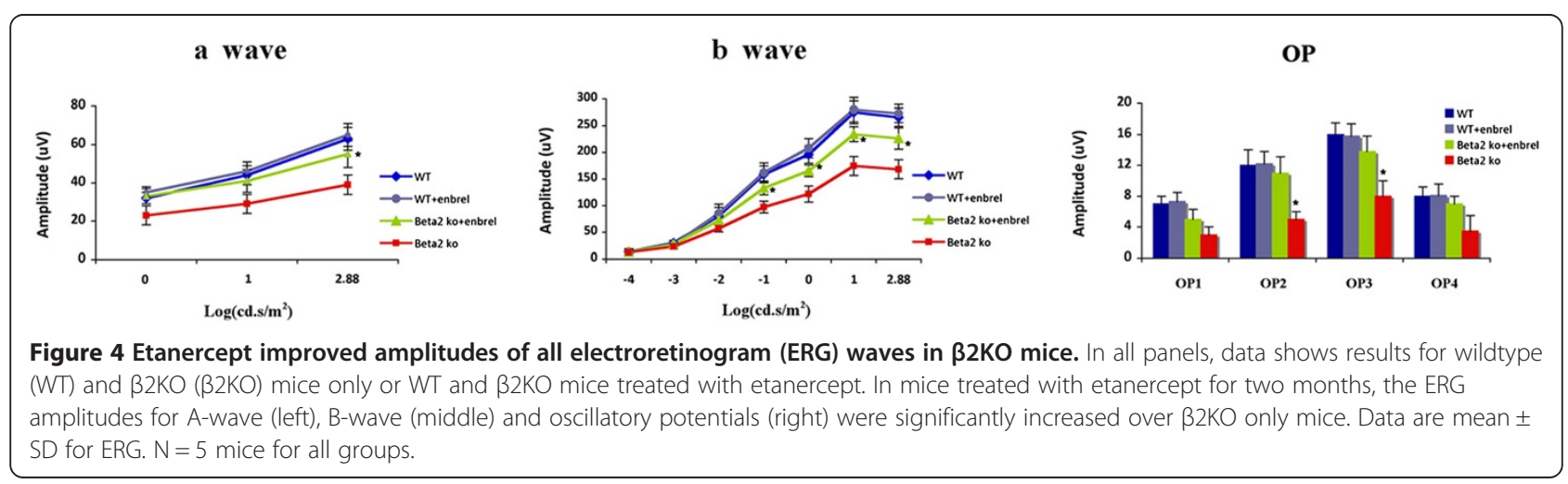


signaling in the inner retina may be correlated to the improvement in the ERG after etanercept treatment.

We focus on our previous work in REC, as $\beta 2 \mathrm{KO}$ mice treated with etanercept likely represent effects of TNF $\alpha$ inhibition on REC only, as we have previously reported that $\beta 2$-adrenergic receptors are key for TNF $\alpha$ actions in Müller cells $[20,21]$. Thus, use of the $\beta 2 \mathrm{KO}$ mice allows us to dissect TNF $\alpha$-mediated effects on insulin signaling in REC versus Müller cells' actions in vivo. Data from etanercept-treated $\beta 2 \mathrm{KO}$ mice suggest that maintenance of normal insulin signaling through TNF $\alpha$ inhibition can reduce inner retinal apoptosis and improve retinal function.

Others have reported that TNF $\alpha$ inhibition using etanercept is effective at reducing diabetic-like changes in the retina $[18,19]$. This study provided novel information on potential reasons for the improvement in diabeticlike changes; that is, reduced TNF $\alpha$-mediated impairment of insulin signaling. Data demonstrate that inhibition of TNF $\alpha$ in $\beta 2 \mathrm{KO}$ mice led to improved insulin receptor phosphorylation on tyrosine 1150/1151, as well as increased anti-apoptotic proteins. Use of etanercept in $\beta 2 \mathrm{KO}$ mice allowed us to dissect TNF $\alpha$-mediated impairment of insulin signal transduction in REC versus Müller cells. Taken together, the present study provides cellular signaling pathways associated with the beneficial effects of etanercept on $\beta 2 \mathrm{KO}$ mice.

\section{Abbreviations}

$\beta 2 \mathrm{KO}$ : $\beta 2$-adrenergic receptor knockout mice; ELISA: enzyme-linked immunosorbent assay; ERG: electroretinogram; IR: insulin receptor; IRS-1: insulin receptor substrate 1; REC: retinal endothelial cells; SOCS3: suppressor of cytokine signaling 3; TNFa: tumor necrosis factor alpha; WT: wildtype; OD: optical density.

\section{Competing interests}

No authors have competing interest with this study.

\section{Authors' contributions}

YJ, QZ, EY completed the studies. JS designed the study and wrote the manuscript. JS, QZ, YJ, EY all edited the manuscript. All authors have read and approved of this manuscript.

\section{Acknowledgements}

This work was supported by the National Eye Institute (R01-EY022330 to JJS); Juvenile Diabetes Research Foundation (2-2011-597 to JJS); Oxnard Foundation (JJS); Research to Prevent Blindness (James C Fleming); National Eye Institute Vision Core Grant (PHS 3 P30 EY013080 to Dianna Johnson).

\footnotetext{
Author details

'Department of Ophthalmology, University of Tennessee Health Science Center, Memphis, TN, USA. ${ }^{2}$ Department of Anatomy \& Neurobiology, University of Tennessee Health Science Center, Memphis, TN, USA. ${ }^{3}$ Department of Pharmaceutical Sciences, University of Tennessee Health Science Center, Memphis, TN, USA. ${ }^{4}$ Department of Ophthalmology, Hamilton Eye Institute, 930 Madison Ave, Suite 768A, Memphis, TN 38163, USA.
}

Received: 19 June 2014 Accepted: 27 July 2014

Published: 20 August 2014

\section{References}

1. Schmidt RE, Plurad SB, Parvin CA, Roth KA: Effect of diabetes and aging on human sympathetic autonomic ganglia. Am J Pathol 1993, 143:143-153.

2. Burnstock $\mathrm{G}$ : Changes in expression of autonomic nerves in aging and disease. J Auton Nerv Syst 1990, 30(Suppl):S25-S34.

3. Steinle JJ, Kern TS, Thomas SA, McFadyen-Ketchum LS, Smith CP: Increased basement membrane thickness, pericyte ghosts, and loss of retinal thickness and cells in dopamine beta hydroxylase knockout mice. Exp Eye Res 2009, 88(6):1014-1019.

4. Panjala SR, Jiang Y, Kern TS, Thomas SA, Steinle JJ: Increased tumor necrosis factor-alpha, cleaved caspase 3 levels and insulin receptor substrate-1 phosphorylation in the beta-adrenergic receptor knockout mouse. Mol Vis 2011, 17:1822-1828.

5. Jiang Y, Zhang Q, Liu L, Tang J, Kern TS, Steinle JJ: beta2-adrenergic receptor knockout mice exhibit A diabetic retinopathy phenotype. PLoS One 2013, 8(7):e70555.

6. Jiang Y, Zhang Q, Ye EA, Steinle JJ: beta1-adrenergic receptor stimulation by agonist Compound $49 \mathrm{~b}$ restores insulin receptor signal transduction in vivo. Mol Vis 2014, 20:872-880.

7. Zhang Q, Guy K, Pagadala J, Jiang Y, Walker RJ, Liu L, Soderland C, Kern TS, Ferry R Jr, He H, Yates CR, Miller DD, Steinle JJ: Compound 49b prevents diabetes-induced apoptosis through increased IGFBP-3 levels. Invest Ophthalmol Vis Sci 2012, 53(6):3004-3013.

8. Jiang Y, Zhang Q, Soderland C, Steinle JJ: TNFalpha and SOCS3 regulate IRS-1 to increase retinal endothelial cell apoptosis. Cell Signal 2012, 24 (5):1086-1092.

9. Jiang Y, Pagadala J, Miller D, Steinle JJ: Reduced insulin receptor signaling in retinal Muller cells cultured in high glucose. Mol Vis 2013, 19:804-811.

10. Steinle JJ, Booz GW, Meininger CJ, Day JN, Granger HJ: Beta 3-adrenergic receptors regulate retinal endothelial cell migration and proliferation. J Biol Chem 2003, 278(23):20681-20686.

11. Walker $R$, Steinle J: Role of beta-adrenergic receptors in inflammatory marker expression in Muller cells. Invest Ophthalmol Vis Sci 2007 48(11):5276-5281.

12. Busik JV, Mohr S, Grant MB: Hyperglycemia-induced reactive oxygen species toxicity to endothelial cells is dependent on paracrine mediators. Diabetes 2008, 57(7):1952-1965.

13. Rui L, Aguirre V, Kim JK, Shulman Gl, Lee A, Corbould A, Dunaif A, White MF: Insulin/IGF-1 and TNF-alpha stimulate phosphorylation of IRS-1 at inhibitory Ser307 via distinct pathways. J Clin Invest 2001, 107(2):181-189.

14. Taniguchi CM, Emanuelli B, Kahn CR: Critical nodes in signalling pathways: insights into insulin action. Nat Rev Mol Cell Biol 2006, 7(2):85-96.

15. Emanuelli B, Peraldi P, Filloux C, Chavey C, Freidinger K, Hilton DJ, Hotamisligil GS, Van Obberghen E: SOCS-3 inhibits insulin signaling and is up-regulated in response to tumor necrosis factor-alpha in the adipose tissue of obese mice. J Biol Chem 2001, 276(51):47944-47949.

16. Emanuelli B, Peraldi P, Filloux C, Sawka-Verhelle D, Hilton D, Van Obberghen E: SOCS-3 is an insulin-induced negative regulator of insulin signaling. J Biol Chem 2000, 275(21):15985-15991.

17. Aguirre V, Uchida T, Yenush L, Davis R, White MF: The c-Jun NH (2)-terminal kinase promotes insulin resistance during association with insulin receptor substrate-1 and phosphorylation of Ser (307). J Biol Chem 2000, 275(12):9047-9054.

18. Joussen AM, Doehmen S, Le ML, Koizumi K, Radetzky S, Krohne TU, Poulaki V, Semkova I, Kociok N: TNF-alpha mediated apoptosis plays an important role in the development of early diabetic retinopathy and long-term histopathological alterations. Mol Vis 2009, 15:1418-1428.

19. Joussen AM, Poulaki V, Mitsiades N, Kirchhof B, Koizumi K, Dohmen S, Adamis AP: Nonsteroidal anti-inflammatory drugs prevent early diabetic retinopathy via TNF-alpha suppression. FASEB J 2002, 16(3):438-440.

20. Walker RJ, Anderson NM, Jiang Y, Bahouth S, Steinle Jj: Role of betaadrenergic receptors regulation of TNF-alpha and insulin signaling in retinal Muller cells. Invest Ophthalmol Vis Sci 2011, 52(13):9527-9533.

21. Walker RJ, Anderson NM, Bahouth S, Steinle JJ: Silencing of insulin receptor substrate-1 increases cell death in retinal Muller cells. Mol Vis 2012, 18:271-279.

doi:10.1186/s12974-014-0137-z

Cite this article as: Jiang et al: Etanercept restores normal insulin signal transduction in $\beta 2$-adrenergic receptor knockout mice. Journal of Neuroinflammation 2014 11:137. 